\title{
Colorimetric determination of fluoride in drinking groundwater using a polymeric zirconium complex of 5-(2-carboxyphenylazo)-8- hydroxyquinoline
}

\author{
Sameer Amereih ${ }^{1}$, Zaher Barghouthi ${ }^{2}$ and Lamees Majjiad ${ }^{1}$ \\ ${ }^{1}$ Palestine Technical University-Kadoori, Tullkarm - Palestine \\ s.bsharat@ptuk.edu.ps \\ ${ }^{2}$ National Agricultural Research Center (NARC), Jenin, Palestine \\ zaher bar@hotmail.com \\ ${ }^{1}$ Palestine Technical University-Kadoori, Tullkarm - Palestine \\ lameesmajiad@yahoo.com
}

\begin{abstract}
A sensitive colorimetric determination of fluoride in drinking water has been developed using a polymeric zirconium complex of 5-(2-Carboxyphenylazo)-8-Hydroxyquinoline as fluoride reagents. The method allowed a reliable determination of fluoride in range of $(0.0-1.5) \mathrm{mg} \mathrm{L}^{-1}$. The molar absorptivity of the complex formation is $7695 \pm 27 \mathrm{~L} \mathrm{~mol}^{-1} \mathrm{~cm}^{-1}$ at 460 $\mathrm{nm}$. The sensitivity, detection limit, quantitation limit, and percentage recovery for $1.0 \mathrm{mg} \mathrm{L}^{-1}$ fluoride for the proposed method were found to be $0.353 \pm 0.013 \mu \mathrm{g} \mathrm{mL}^{-1}, 0.1 \mathrm{mg} \mathrm{L}^{-1}, 0.3 \mathrm{mg} \mathrm{L}^{-1}$, and $101.7 \pm 4.1$, respectively.
\end{abstract}

Key words: Colorimetric method; Drinking groundwater; Fluoride; Polymeric zirconium azo dye complex.

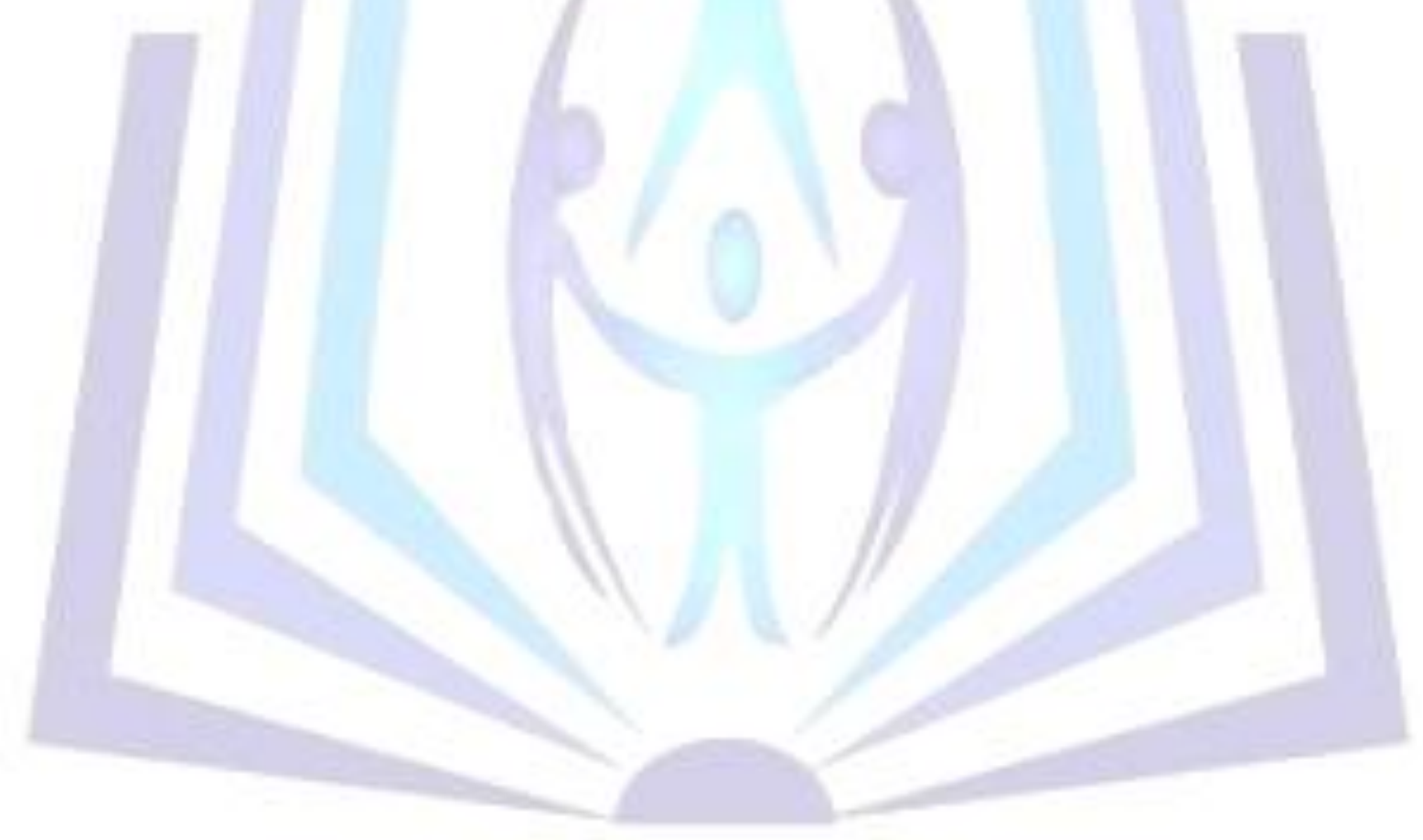

\section{Council for Innovative Research}

Peer Review Research Publishing System

Journal: Journal of Advances in Chemistry

Vol. 4, No. 2

editor@cirworld.com

www.cirworld.com, member.cirworld.com 


\section{INTRODUCTION}

According to World Health Organization (WHO) 2006, ${ }^{1}$ fluoride can cause significant effects in people through drinking water. There is a narrow margin between the desired and harmful doses of fluoride. ${ }^{2}$ Low concentration of fluoride in drinking water have been considered beneficial to prevent dental carries, ${ }^{3,4}$ but excessive exposure to fluoride can give rise to a number of adverse effects such as fluorosis. ${ }^{1,5,6-9}$ WHO has set a limit value of $1.5 \mathrm{mg} \mathrm{L}^{-1}$ of fluoride in drinking water. ${ }^{10,11}$ Therefore, an accurate, simple, rapid and cost effective analytical method is of high importance. ${ }^{12}$

Spectrophotometric methods, which are widely used in the determination of fluoride, are based on the reaction of fluoride with colored metal chelate complexes, producing either a mixed-ligand ternary complex or replacement of the ligand by fluoride to give a colorless metal-fluoride complex and the free ligand with a color different of the metal-ligand complex. ${ }^{13}$

The present work aimed to use the polymeric zirconium complex of 5-(2-carboxyphenylazo)-8-hydroxyquinoline $\left(\mathrm{LH}_{2}\right)$ ligand for colorimetric determination of fluoride in in the range $0.0-2.0 \mathrm{mg} \mathrm{L}^{-1}$, compatible with the WHO limit value of 1.5 $\mathrm{mg} \mathrm{L}^{-1}$.

\section{MATERIALS AND METHODS}

\subsection{Apparatus}

Beckman DU-7500 single beam spectrophotometer with $1.0 \mathrm{~cm}$ quartz cells was used for wavelength scanning and for spectral studies. Hitachi U- 1500 UV/Vis single beam spectrophotometer with $1.0 \mathrm{~cm}$ quartz cells was used for the absorbance measurements at fixed wavelength.

\subsection{Reagents and chemicals}

8-Hydroyquinoline provided by Mallinckrodt (ACS reagent, 4969), anthranilic acid provided by Aldrich (98\%, A89855) and Zirconium (IV) oxide chloride (p. a, 108917) provided by Merck were used without any further purification. All the chemicals were of analytical reagent grade except where stated otherwise. Solutions were prepared using double distilled water. 5-(2-Carboxyphenylazo)-8-hydroxyquinoline $\left(\mathrm{LH}_{2}\right)$ ligand solution and the polymeric zirconium complex solution were prepared using methanol from Carl Roth $\mathrm{GmbH}(99.9 \%$ p. a., ACS, ISO, 46275). Standard fluoride stock solution was prepared by dissolving $0.1382 \mathrm{~g}$ of sodium fluoride provided by Merck (ACS reagent, 106449) in $250 \mathrm{ml}$ water. The stock solution was further diluted as needed.

\subsection{Preparation of the azo dye (LH2) and metal complexes solutions}

$\mathrm{LH}_{2}$ azo dye was prepared using anthranilic acid as a source of diazonium salt, and 8-hydroxyquinone as a coupler. Job's method of continuous variation was adopted for the determination of the composition of the colored complex. ${ }^{14,15}$ Zirconium to $\mathrm{LH}_{2}$ ligand ratio was also studied by preparing complexes with the most common molar ratios $(1: 1,1: 2,1: 3$, $2: 1,3: 1,2: 3$, and 3:2) to enable comparison between the spectra of these different complexes. The blank was prepared by the same procedure using the solvent instead of zirconium ionic solution.

Zirconium to ligand ratio was found to be $1: 1$. Thus, the complex solutions for the spectrophotometric measurements were prepared as 1:1 ratios from zirconium and ligand of $4 \times 10^{-4} \mathrm{M}$ in methanol solutions, and the solutions were then diluted to the concentration of $\left(\approx 5.25 \times 10^{-5} \mathrm{M}\right)$ suitable for the spectrophotometric measurements.

\subsection{Reaction of fluoride with the prepared complex solutions}

Various amounts of fluoride in the range of $0-2 \mathrm{mg} \mathrm{L}^{-1}$ were added to $25 \mathrm{ml}$ volumetric flask containing the polymeric zirconium complex solution of $\mathrm{LH}_{2}$ in methanol $\left(5.25 \times 10^{-5} \mathrm{M}, 24.5 \mathrm{ml}\right)$. The solution was made up to volume with water. The absorbance was measured at the wavelength of maximum difference $491 \mathrm{~nm}$ in the electronic spectra between the ligand and the complex. The spectra for the reaction of different amounts of fluoride with the complex were compared.

\subsection{Determination of fluoride in real drinking groundwater samples}

The method under investigation was tested using three real drinking water samples which had been collected and analysed by the Central Public Health Laboratory of the Ministry of Health, Palestine, which is responsible for managing water quality.

Samples were collected in September 2012 from two groundwater wells in Jenin District (Yamoon well and Saadeh well) and one groundwater well in Tulkarm District (Tulkarm well). Fluoride was analysed colorimetrically using SPADNS as fluoride reagent and Hack - DR/2010 as spectrophotometer. Nitrate, sulfate, chloride, and other characteristic data of the three samples are given in table 1. Because of the low content of fluoride in the West Bank groundwater resources, fluoride was measured after spiking the samples by $0.5 \mathrm{mg} \mathrm{L}^{-1}$ fluoride. Finally, the obtained results were compared with that reported by the Central Public Health Laboratory using SPADNS method (table 1 and table 2). 
Table 1. Analytical data of the three water samples analysed by Ministry of Health laboratories

\begin{tabular}{|l|c|c|c|c|c|c|c|c|}
\hline & Well & $\mathbf{p H}$ & $\begin{array}{c}\text { Conductivity } \\
\text { Micro.S cm }\end{array}$ & $\begin{array}{c}\text { Fluoride } \\
\mathbf{m g ~ L}\end{array}$ & $\begin{array}{c}\text { Nitrate } \\
\mathbf{m g ~ L}\end{array}$ & $\begin{array}{c}\text { Chloride } \\
\mathbf{m g ~ L}^{-1}\end{array}$ & $\begin{array}{c}\text { Sulfate } \\
\mathbf{m g ~ L}^{-1}\end{array}$ & $\begin{array}{c}\text { TDS } \\
\mathbf{M g ~ L}^{-1}\end{array}$ \\
\hline Sample 1 & Yamoon & 7.28 & 841.00 & 0.46 & 4.50 & 186.00 & 54.00 & 420.00 \\
\hline Sample 2 & Saadeh & 7.52 & 636.00 & 0.38 & 10.68 & 101.77 & 37.30 & 318.00 \\
\hline Sample 3 & Tulkarm & 7.30 & 648.00 & 0.26 & 14.66 & 89.44 & 41.00 & 401.97 \\
\hline
\end{tabular}

Table 2. Sensitivity, detection limit, quantification limit, and recovery of the proposed spectrophotometric method.

\begin{tabular}{|c|c|}
\hline Parameter & Values at $491 \mathrm{~nm}$ \\
\hline Sensitivity $\left[\mu \mathrm{g} \mathrm{mL}^{-1}\right]$ & $0.353 \pm 0.013$ \\
\hline Detection limit $\left[\mathrm{mg} \mathrm{L}^{-1}\right]$ & 0.1 \\
\hline Quantification limit [mg L $\left.\mathrm{L}^{-1}\right]$ & 0.3 \\
\hline Recovery of $1.0 \mathrm{mg} \mathrm{L}^{-1} \%$ & $101.7 \pm 4.1$ \\
\hline Recovery of $1.5 \mathrm{mg} \mathrm{L}^{-1} \%$ & $104.9 \pm 5.1$ \\
\hline Recovery of sample $1+0.5 \mathrm{mg} \mathrm{L}^{-1}$ Fluoride $\%$ & $102.3 \pm 4.6$ \\
\hline Recovery of sample $2+0.5 \mathrm{mg} \mathrm{L}^{-1}$ Fluoride $\%$ & $105.1 \pm 3.8$ \\
\hline Recovery of sample $3+0.5 \mathrm{mg} \mathrm{L}^{-1}$ Fluoride $\%$ & $103.1 \pm 3.2$ \\
\hline
\end{tabular}

\section{RESULTS AND DISCUSSION}

Through the search for the best fluoride reagent, ligands containing groups capable of holding metals in stable combination were examined. This includes four main types: 1, 2-dihydroxyanthraqunion and its analogs; o,o'-dihydroxyazo compounds; azosalicylic acids; and o-nitrosophenols or o-quinone monoximes. ${ }^{16}$ The best results were obtained with $\mathrm{LH}_{2}$ ligand. The polymeric zirconium complex of this ligand is described in this study.

\section{1. $\mathrm{LH}_{2}$ ligand and its polymeric zirconium complex}

$\mathrm{LH}_{2}$ ligand was prepared and characterized. ${ }^{17,18}$ Its electronic absorption spectra displays three bands (figure 1). The two small bands observed at 289 and $348 \mathrm{~nm}$ may be ascribed to the excitation of the $\pi$-electrons, which are localized on the quinoline ring. While the third band at $489 \mathrm{~nm}$ maybe assigned to charge transfer within the molecule through $-\mathrm{N}=\mathrm{N}-$ linkage. The molar absorptivity of the $\mathrm{LH}_{2}$ at $489 \mathrm{~nm}$ is $29990 \mathrm{~L} \mathrm{~mol}^{-1} \mathrm{~cm}^{-1}$.

The molar ratio of zirconium to $\mathrm{LH}_{2}$ ligand in the complex was determined by both of Job's method of continuous variations and by spectrophotometrical comparison between the most common metal to ligand ratios $(1: 1,1: 2,1: 3,2: 1,3: 1,2: 3$, and 3:2). The obtained results indicated that zirconium to $\mathrm{LH}_{2}$ ligand ratio can be 1:1,1:2, or 1:3. The reaction of zirconium $\mathrm{LH}_{2}$ $1: 1,1: 2$, or $1: 3$ complexes with fluoride showed that the maximum difference in the absorption spectra was occurred with the polymeric $1: 1$ complex. Therefore, the further discussion will be focused on this complex.

$\mathrm{Zr}\left(\mathrm{LH}_{2}\right)$ complex is light orange. The light orange color is due to both of the hypsochromic shift (blue shift) and the hypochromic shift (decreasing in the absorbance) that take place after the complexation with zirconium (figure 1). These two shifts - in the wavelength and in the absorbance - are responsible for the changes in the color between the ligand and its zirconium complex. Indeed, there is a decrease in the wavelength of the maximum absorption of the complex by $29 \mathrm{~nm}$ less than that of the ligand. This leads to a change in the color from red to light orange.

The absorption spectra of $\operatorname{Zr}\left(\mathrm{LH}_{2}\right)$ 1:1 complex displays two bands at 259 and $460 \mathrm{~nm}$ as shown in figure 1. The molar absorptivity at these two bands is $7490 \pm 127$ and $7695 \pm 27 \mathrm{~L} \mathrm{~mol}^{-1} \mathrm{~cm}^{-1}$ respectively. In the present work, $\mathrm{Zr}\left(\mathrm{LH} \mathrm{H}_{2}\right)$ complex was dissolved in methanol. The stability of the $\mathrm{Zr}\left(\mathrm{LH}_{2}\right)$ complex in methanol solution was examined by measuring the absorbance of the solution at different time intervals during two weeks and the complex remained stable. 


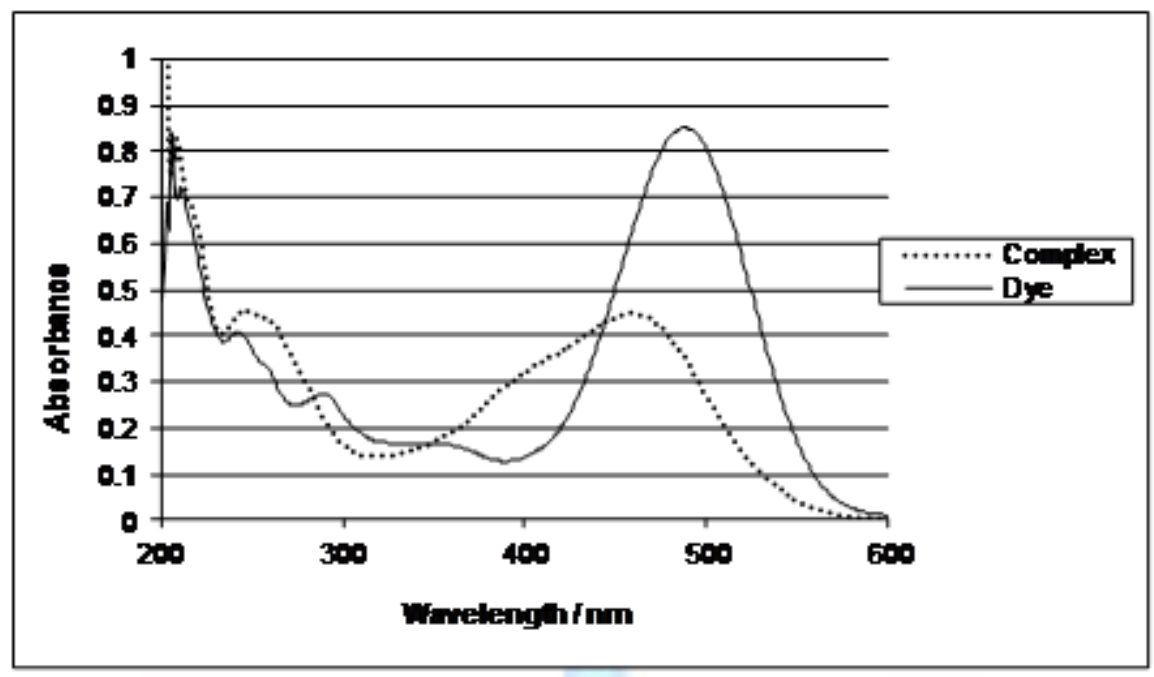

Fig. 1. Absorption spectra of $\mathrm{LH}_{2}$ ligand and its polymeric zirconium complex in methanol at $5.25 \times 10^{-5} \mathrm{M}$.

\subsection{Reaction with fluoride}

Fluoride ions, which form very stable complex ions with zirconium, react to displace the dye molecules. Quantitative determination are made by measuring the ratio of displaced free dye to the color of the unchanged lake. ${ }^{19}$ In this work, fluoride reacts with the light orange zirconium $\mathrm{LH}_{2}$ complex to produce a colorless zirconium fluoride complex by replacement of the $\mathrm{LH}_{2}$ by fluoride and liberating of the free ligand. This leads to a change in the color from that of the complex, light orange to the color of the free ligand, red according to the equation below.

$$
\mathrm{Zr}\left(\mathrm{LH}_{2}\right) \text { light orange }+6 \mathrm{~F}^{-} \rightarrow \mathrm{ZrF}_{6}^{-3} \text { colorless }+\mathrm{LH}_{2} \text { red }
$$

The conversion of the color and the absorption spectra from that of the complex to the color and spectra of the ligand is will illustrated in figure 2 which reflects the changes in the spectra of the complex in the course of the titration of fluoride. The absorption spectra of the reaction of fluoride with the zirconium $\mathrm{LH}_{2}$ complex showed that fluoride interacts to cause an increase in absorbance of the zirconium complex at $491 \mathrm{~nm}$, and a decrease in absorbance at 263 and $383 \mathrm{~nm}$ due to the formation of zirconium fluoride complex and releasing of the free ligand. The absorbance of the zirconium complex is related linearly at $491 \mathrm{~nm}$ to the concentration of fluoride in the range 0.0 to $1.5 \mathrm{mg} \mathrm{I}^{-1}$, the squared correlation coefficient $R^{2}$, is 0.998 . The equation of the linear calibration curve at $491 \mathrm{~nm}$ is $(y=0.3533 x+0.3968)$. On the other hand, the absorbance of the zirconium $\mathrm{LH}_{2}$ complex is not related linearly at 263 and $383 \mathrm{~nm}$ to the concentration of fluoride.

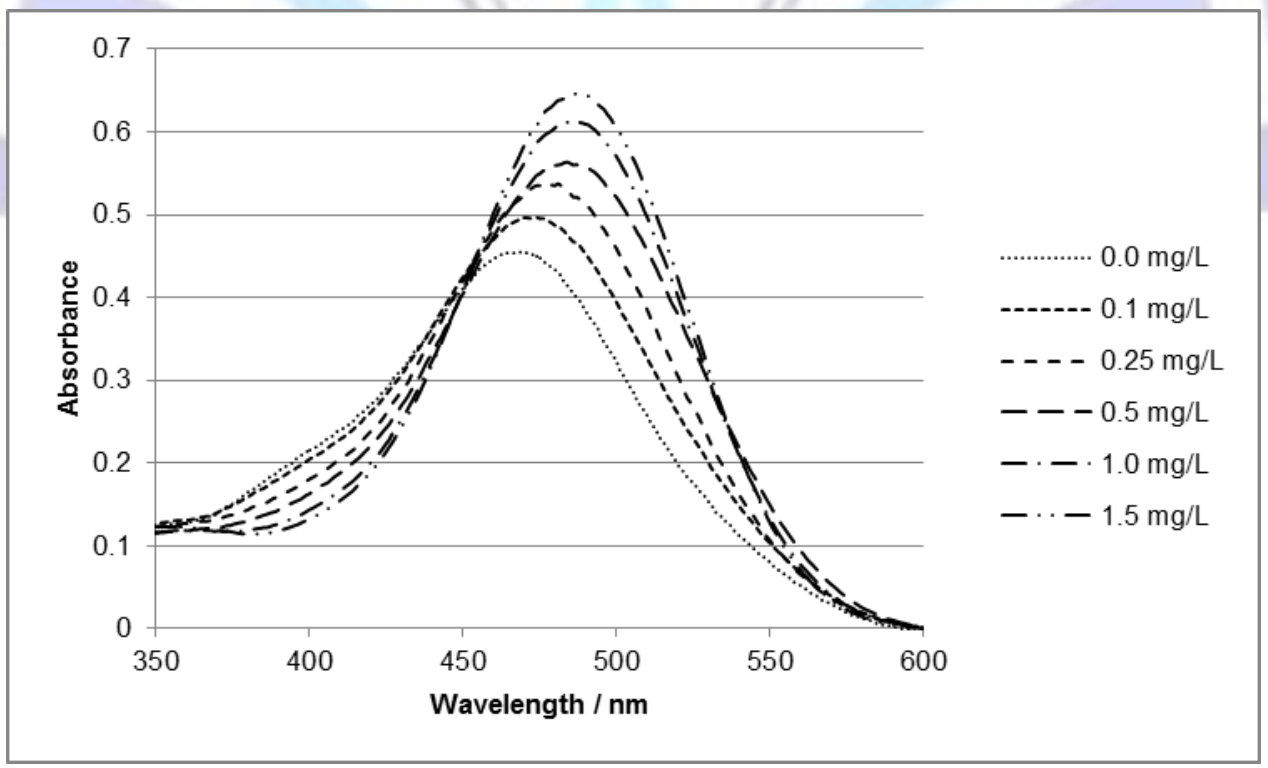

Fig. 2: Changes in the absorption spectra of the complex due to addition of various amounts of fluoride. 
The proposed spectrophotometric method was tested by measuring fluoride contents in water samples which had been already analysed by the Central Public Health Laboratory. The recovery of fluoride by the proposed method (table 2) is in good agreement with that reported by the Central Public Health Laboratory using SPADNS colorimetric method (table 1).

The sensitivity, detection limit, limit of quantification, and the recovery of $1.0,1.5 \mathrm{mg} \mathrm{L}^{-1}$ fluoride of the $\mathrm{Zr}\left(\mathrm{LH}_{2}\right) 1: 1 \mathrm{complex}$ for the spectrophotometric determination of fluoride at $491 \mathrm{~nm}$ are given in table 2 . The sensitivity was taken as the average of the slope of the calibration curve for five replicates. The detection limit and the limit of quantification were calculated as $(3.3 \sigma / S)$ and $(10 \sigma / S)$ respectively, where $\sigma$ is the standard deviation of response and $S$ is the slope of the calibration curve. The recovery was measured as the average of 10 replicate.

The interference studies were done by measuring the influence of the anions such as chloride, nitrate, and sulfate in such concentration commonly found in the natural water on the determination of 1.0 and $1.5 \mathrm{mg} \mathrm{L}^{-1}$ fluoride. Chloride and nitrate which were added in the range of $100-500$ and $5-100 \mathrm{mg} \mathrm{L}^{-1}$ respectively do not interfere with the determination of fluoride. Sulphate interferes with the most visual and photometric methods for determination of fluoride by its competition with fluoride to form a complex with the metal and therefore it results in higher concentrations. ${ }^{20,21}$ In the present work, when the amount of sulfate is higher than $100 \mathrm{mg} \mathrm{L}^{-1}$, it interferes with determination of fluoride by causing a positive error of about $20 \%$. This error can be overcome by precipitating sulphate in cold by the addition of aqueous barium chloride solution and aqueous agar-agar solution, then to separate the precipitate by filtration. ${ }^{22}$

Interferences may also be referred to the presence of metal ions such as aluminium, iron, or magnesium that give a colour with the dye. The possibility of this type of interferences is low. ${ }^{12,17}$ However, when the sample solution is expected to contain a large amount of these cations, it is recommended to mask the metals interferences by adding complexing agents such as DCTA (trans- 1,2- aminocyclohexane- N,N,N',N'- tetraacetic acid) ${ }^{23}$ or EDTA (ethylenediaminetetraacetic acid. ${ }^{24}$

\section{CONCLUSIONS}

Zirconium complexes of $\mathrm{LH}_{2}$ ligand were examined as spectrophotometric reagent for fluoride determination. The polymeric zirconium complex was used successfully as colorimetric reagent for determination of fluoride in the range 0.0 to $1.5 \mathrm{mg} \mathrm{L}^{-1}$. Due to its simplicity and high sensitivity, the proposed method can be recommended as new reagent for controlling the amount of fluoride in drinking water.

\section{ACKNOWLEDGEMENTS}

The author s thanks Professor Walter Kosmus from the Analytical Chemistry Institute in Karl-Franzens the University of Graz, Austria, for his advices, suggestions, ideas, comments, helpful discussions, and for his supervision of the Ph. D. research. The authors thank the director (Mr. Ibrahim Salem) and the staff of the Central Public Health Laboratory, Ramallah, for their cooperation and for sharing their data.

\section{REFERENCES}

[1] WHO, 2006. Fluoride in Drinking-Water, IWAPublishing: London, -3, 83-95

[2] Czarnowski, W., Wrzesniowska, K. and Krechniak, 1996. Fluoride in drinking water and human urine in Northern and Central Poland. J. Sci. Total Environ. 191, 177-184.

[3] Maliyekkal, S. M., Shukla, S., Philip, L. and Nambi, I. M. 2008. Enhanced fluoride removal from drinking water by magnesia-amended activated alumina granules. Chem. Eng. J. 140, 183-192.

[4] Qin, X., Wang, S., Yu, M., Zhang, L., Li, X.;, Zuo, Z., Zhang, X. and Wang, L. 2009. Child skeletal fluorosis from indoor burning of coal in Southwestern China. J. Environ. Public Health, 2009, 1-7.

[5] Sunitha, V., Reddy, B. R. and Srinivas, B. 2004. Fluoride in ground water of Anantapur town, Anantapur District, Andhra Pradesh, India. J. Appl. Geochem. 6, 368-372.

[6] Arminta, M. A. and Segovia, N. 2008. Arsenic and fluoride in the groundwater of Mexico. Environ. Geochem. Health. $30,345-353$.

[7] Aldrees, A. M. and Al-Manea, S. M. 2010. Fluoride content of bottled drinking waters available in Riyadh, Saudi Arabia. Saudi Dent. J. 22, 189-193.

[8] Arveti, N., Sarma, M. R. S., Atikenhead-Peterson, J. A. and Sunil, K. 2011. Fluoride incidence in groundwater: a case study from Talupula, Andhra Pradesh, India. Environ. Monit. Assess. 172, 427-443.

[9] Dunne, K. and Verrell, P. 2011. Acute effect of exposure to sodium fluoride on the red compost earthworm eisenia fetida: Lethality and avoidance behavior. Fluoride, 44, 210-214.

[10] WHO, 2004. Guideline for Drinking-Water Quality. Recommendation; $2^{\text {nd }}$ ed., Vol. 1, World Health Organization: Geneva, 375-377.

[11] Rafique, T., Naseem, S., MBhanger, M. I. and Usmani, T. H. 2008. Fluoride ion contamination in ground water of Mithi Sub-district, the Thar Desert, Pakistan. Environ. Geol. 56, 317-326.

[12] Barghouthi, Z. and Amereih, S. 2012. Spectrophotometric determination of fluoride in drinking water using aluminium complexes of triphenylmethane dyes. Water SA. 38, 543-548. 
[13] Einaga, H.and Iwasaki, I. 1981. Spectrophotometric study of the reaction of zirconium with chrome azurol S and fluoride. Talanta, 28, 889-900.

[14] Werner, L. and Boltz, D. F. 1971. Theory of continuous variations plots and a new method for spectrophotometric determination of extraction and formation constant. Anal. Chem. 43, 1265-1272.

[15] Werner, L. and Boltz, D. F. 1971. Spectrophotometric determination of extraction constants of certain metal 1 pyrrolidinecarbodithioates. Anal. Chem. 43, 1273-1277.

[16] Venkatarman, K. 1952. The Chemistry of Synthetic Dyes; Acadamic Press: New York, 1952, pp. 210 , and 272.

[17] Barghouthi, Z. and Amereih, S. 2013. Field determination of fluoride in drinking water using a polymeric aluminium complex of 5-(2-carboxyphenylazo)-8-hydroxyquinoline impregnated paper. Intern. J. Environ. Anal. Chem. 93, 565577.

[18] El-Sonbati, A. Z., Belal, A. A. M., El-Wakeel, S. I. and Hussien, M. A. 2004. Stereochemistry of new nitrogen containing heterocyclic compound. $X$. supramolecular structures and stereochemical versatility of polymeric complexes. Spectrochim. Acta A. 60, 965-972.

[19] Lambert, J. L. 1954. Determination of fluoride ion using a monohydroxy azo dye-thorium lake. Anal. Chem. 26, 558560.

[20] Ruzicka, J. A., Jakschova, H. and Marklas, L. 1966. Determination of fluoride in bones and teeth with xylenol orange Talanta, 1966, 13, 1341-1344.

[21] Price, M. J. and Walker, O. J. 1952. Determination of fluoride in water. Anal. Chem. 24, 1593-1595.

[22] Dixon, E. J. 1970. Determination of micro amounts of fluoride with zirconium and solochrome cyanine R. Analyst. 95, 272-977.

[23] Nishimoto, J., Yamada, T. and Tabata, M. 2001. Solvent extraction and fluorometric determination of fluoride ion at ppb level in the presence of large excess of aluminum(III) and iron(III) by using an expanded porphyrin, sapphyrin. Anal. Chim. Acta. 428, 201-208.

[24] Snell, F. D. 1978. Photometric and fluorometric methods of analysis metals; John Willy \& Sons: New York, pp. 41, 467, 659, 693, 1179, 1344, 1412, 1857, 1887, and 1916.

\section{Author' biography with Photo}

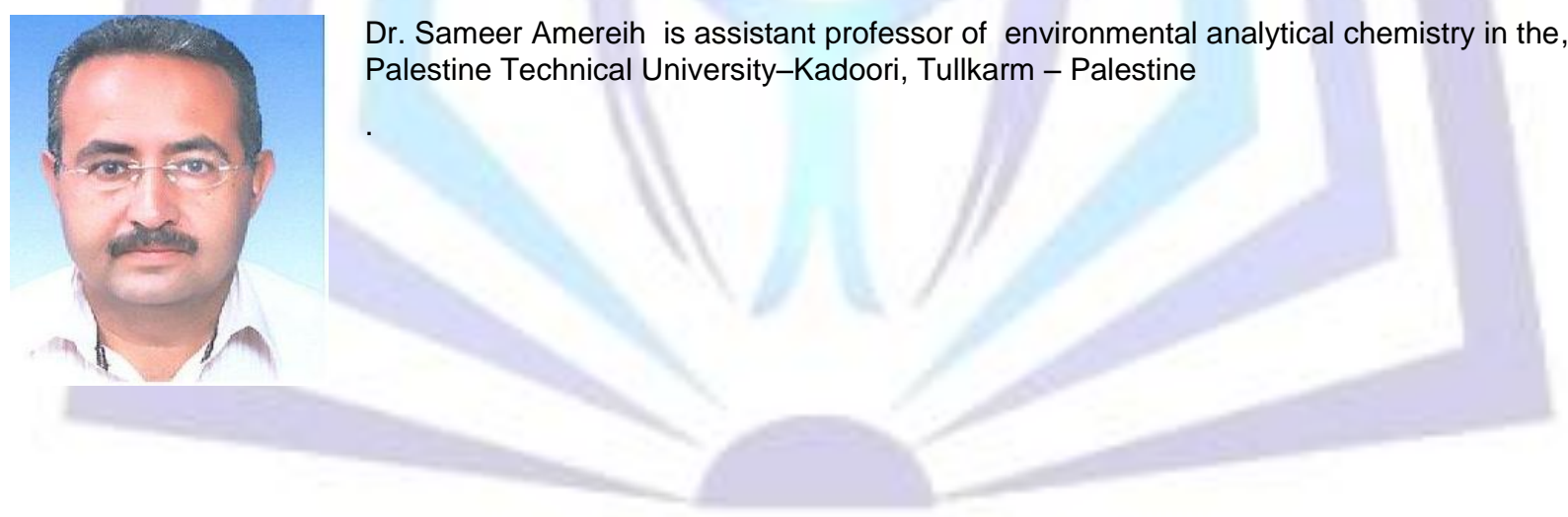

